\title{
PRODUCTION RESPONSE TO PRICES IN THE COCONUT INDUSTRY OF PAPUA NEW GUINEA: A COMMENT ON THE METHODOLOGY AND A RE-ESTIMATION
}

\author{
Premasiri J. Gunawardana ${ }^{1}$
}

\section{Introduction}

Analytical studies on the supply response of growers in the major crop sectors in Papua New Guinea (PNG) are scarce. For this reason, De Silva, Kiele and Lagap (DKL, 1987) ${ }^{2)}$ must be congratulated for their pioneering attempt at analysing the production response to changes in prices in the coconut sector of the country. However, in their analysis there are several short-comings of a methodological and empirical nature. The purpose of this note is to highlight these shortcomings and offer altemative estimations and interpretations about the nature of production response to price changes in the coconut sector.

\section{DKL's Estimates And Their Shortcomings}

DKL specified the following supply function to analyze the production response of coconut growers:

$$
\mathrm{Y}=\mathrm{f}(\mathrm{P}, \mathrm{T}, \mathrm{A})
$$

where $\mathrm{Y}$ is copra output, $\mathrm{P}$ is pzice of copra, $\mathrm{T}$ is the time trend variable and $\mathrm{A}$ is a dummy variable included to account for structural change in production organization in the coconut sector (from large holder dominance to small holder dominance since 1977).

In the presentation of the results, the variable A has been dropped by DKL because of the statistically insignificant coefficient attached to this variable. The equations estimated by DKL with price lagged on $\left(\mathrm{P}_{\mathrm{t}_{-} 1}\right)$, seven $\left(\mathrm{P}_{\mathrm{t}_{-} 7}\right)$, and eleven $\left(\mathrm{P}_{\mathrm{t}_{-11}}\right)$ years are reproduced below

$$
\begin{aligned}
& \log Y=5.0141+0.012942 \log P_{t_{-} 1}+0.0001 T \\
& \log Y=5.0082+0.00011 \log P_{t_{-} 7}+0.00632 T \\
& \log Y=5.0225+0.00017 \log P_{t_{-} 11}+0.0064 T
\end{aligned}
$$

Based on the above equations, DKL calculated the short-nm price elasticity of supply at 0.012942 (equation 2), a "mediumterm" price elasticity af 0.00011 (equation 3 ) and a "long-term price elasticity at 0.00017 (equation 4 ).

DKL have estimated different specifications of their basic supply fimction with price lags ranging from 1 to 15 years. In doing so, DKL have implicity assumed that coconut growers make supply decisions in the current time period according to price received by them for copra even 15 years ago. Whatever the price lag chosen, the model employed by DKL only allows an estimation of short-run supply response and hence short-nm price elasti city of supply. The inclusion of price lagged 7 years or 15 years does not pennit one to estimate long-run supply response or longrun price elasticities; they still show the short-run response. Thus, DKL have erred in caffing the elasticities they calculated on the basis of estimated equations with price lagged 7 years and 11 years the "medium-term" and "long-term" elasticities, respectively. Subject to errors of the Consumer Price

\footnotetext{
${ }^{1}$ Presentely in the School of Agriculture, La Trobe University, Bundoora, Victoria 3083, Australia.

${ }^{2}$ De Silva N.T.M.H., Kiele L.J. and Lagap AF (1987) 'Production Response to Prices in the Coconut Industry of Papua New Guinea”, CORD Vol. III No. 2 July 2987 pp, 2-20.
} 
Index data used (see below), the equation with a price lagged one year (equation 2) provides DKL's "best" estimate of the short-mn supply elasticity other two equations are quite unnecessary.

The inclusion of the dummy variable (A) in the supply func tion (equation 1) only allows one to estimate two supply func tions with different intercepts for the two periods considered: from 1962 to 1976 and from 1977 to 1985 . It does not provide a basis to infer anything about different supply responses or short nin price elasticities in different situations of small holder domin ance viz-a-viz large holder dominance. It appears that DKL believe that these different supply responses can be analysed by the in clusion of an intercept dummy in the supply response equation This is another shortcoming of the DKL's analysis. To analyse the different supply responses in the two periods one must reestimate the supply functions with slope dununies with respect to the price variable.

Another problein with DKL's estimation concems the Consuiner Price Index (CPI) data used to deflate the price of copra. Although DKL clairn that year 1985 was used as the base, it -appears that the indices given on different bases (e.g. 1962 $=100,1971=100$ and 1977-100) have not been converted to a common basis (i.e. 1985-100). Thus, the CPI data used by DKI exhibit quite unacceptable swings: for example, from 82.82 in 1973 to 103.9 in 1974 and from 127.20 in 1977 to 62.27 in 1978. The use of these apparently inaccurate CPI data must have seriously affected the elasticity estimates made by DKL.

\section{Analysis of Lons-ran Supply Response}

Analysis of long run supply response and the estimation of long run pzice elastcities of supply require specification of a different supply function which takes in account the process of continuous adjustment of output by producers towards a long-run equflibrium. The long-run adjustment process can be analysed by employing "Nerlovian adjustment lag model" (Nerlove, 1958), which includes lagged output as an independent variable in addition to price of output. The lagged output terin serves as a proxy for all previous adjustments to prices. An additional argument is that current output depends also on the output in the previous period. Ms is so because in the short-run, an instantaneous adjustment of output to a change in price is constrained by factors such as "...resource fixity, managerial ability of farmers, and habitual production pattems" (Tamek and Robinson, 1982, p. 316).

When a supply function is estimated with piice $(\mathrm{P})$ and lagged output $\left(\mathrm{Y}_{\mathrm{t}_{1} 1}\right)$ variables, the short-run supply response is indicated by the coefficient estimated for the price variable, but the longrun supply response (adjustinent) is larger by a factor determined by the estimated coefficent for lagged output variable. Therefore, the degree of adjustment (coefficient of adliustment) is detezniined by subtracting the coefficient for lagged output variable from one. To derive the long-run price elasticity, the short-run price elasticity is divided by the coefficient of adjustment. Formally, the procedure is as folows :

Step 1: Estimate the supply response equation

$$
\mathrm{y}_{\mathrm{t}}=\mathrm{a}+\mathrm{bP}+\mathrm{cY}_{\mathrm{t} \_1}
$$

Step 2: Calculate the Coefficient of adjustment

$$
\mathrm{r}=1-\mathrm{c}\left(\mathrm{Y}_{\mathrm{t} \_1}\right)
$$

Step 3: Calculate thp. sholt-mn plice elasticity (es)

$$
\begin{aligned}
& \mathrm{es}=\mathrm{b}(\mathrm{P} / \mathrm{Y})(\text { for linear function }) \\
& \mathrm{es}=\mathrm{b}(\text { for log-linear function })
\end{aligned}
$$


Step 4: Calculate the long-run price elasticity (el):

$$
\mathrm{el}=\mathrm{es} / \mathrm{r}
$$

One would normally expect a coefficient of adjustment of greater than zero and less than one, implying a partial adjustment. Zero coefficients are ruled out because they imply infinite longterm price elasticities with fmite short-run price elasticities, while unitary coefficients are unacceptable since it is not reasonable to expect a perfect adjustment where desired or expected output exactly equals actual or realised output.

A common result is that long-run elasticity is roughly twice as large as the short-run elasticity. DKL calculate a smaller "longterm" elasticity and provide expianations as to why this may be possible. But the real problem is the snag in their method of estimation.

\section{Re-estimatiomof Copra Supply Functions}

First, the copra supply function as specifled by DKL was re-estimated, using price and quantity data provided in DKL's paper. However, the prices were deflated by a re-chained Consumer Price Index (1985 = 100 ; see Appendix 1). Since CPI data for this index were available from 1962, and because of the inclusion of one year lag, the period of the analysis is confmed to 23 years from 1963 to 1985 (see Appendix 2). As in DKL paper, the log-linear functional form was employed in the statistical estimation.

A prellminary run of the regressions indicated that, as in DKL's estimation, the coefficient attached to the dummy variable (A) was not statistically significant even at 10 per cent level. Hence it was decided to drop this variable from the subsequent specifications. Only the results of the estimations without the variable $\mathrm{A}$ are reported below.

$\begin{array}{lcc}\text { Supply Function: } \log \mathrm{Y}_{\mathrm{t}}=\mathrm{f}\left(\log \mathrm{P}_{\mathrm{t}_{-} 1}, \mathrm{~T}\right) & (6) \\ \text { Coefficient } & \mathrm{t} \text { statistic } \\ \text { Constant } & 4.612 & 35.36 \\ \text { Log } \mathrm{P}_{\mathrm{t}_{-} 1} & 0.158 & 3.37 \\ \mathrm{~T} & 0.008 & 9.01 \\ \mathrm{R}^{2}=0.82, & \mathrm{R}^{2}=0.80, \mathrm{~F}=44.25, \text { D.W. }=1.63\end{array}$

All the coefficients are significant at 1 per cent level.

In equation (6), $Y_{t}$ is current copra production in tonnes, $p_{t-1}$ is copra price lagged one year (Kina/tonne) deflated by Consumer Price Index $(1985=100)$, and $\mathrm{T}$ is time trend variable which is included to account for the effectes of new plantings and replantings on the supply over the period considered.

The short-run price elasticity of 0.158 , estimated on the basis of equation (6), represents a remarkable improvement over the DKL estimate. The estimate of price elasticity indicates that, in the short-run, a 10 per cent increase in price leads to about 1.6 percent increase in copra production. Thus it is reasonable to conclude that price responsiveness of coconut growers in PNG is much Mgher than that imphed in DKL paper, although in technical terms copra production is stiH "inelastic" with respect to price. 
To examine whether there is any difference of supply elasticities between the periods prior to 1977 and after 1977, another equation was estimated including slope dummies with respect to the price variable. The results of this estimation are reported below.

Supply Function: $\log \mathrm{Y}_{\mathrm{t}}=\mathrm{f}\left(\log \mathrm{P} 1_{\mathrm{t}_{-} 1}, \log \mathrm{P} 2_{\mathrm{t}_{-}}, \mathrm{T}\right)$

where, $\mathrm{PI}_{\mathrm{t} \_1}=1 \times \mathrm{P}_{\mathrm{t} \_1}$ for 1963-76

$$
=0 \times \mathrm{P}_{\mathrm{t}_{-}} \text {for } 1977-85 \text {, and }
$$

$\mathrm{P} 2_{\mathrm{t}_{-} 1}=0 \times \mathrm{P}_{\mathrm{t} \_1}$ for $1963-76$

$$
=1 \times \mathrm{P}_{\mathrm{t} \_1} \text { for 1977-85. }
$$

$\begin{array}{lcc} & \text { Coefficient } & \mathrm{t} \text { Statistic } \\ & & \\ \text { Constant } & 4.607 & 34.93 \\ \log P 1_{\mathrm{t} \_} 1 & 0.164 & 3.439 \\ \log P 2_{\mathrm{t}} 1 & 0.17 & 3.46 \\ \mathrm{~T} & 0.007 & 5.225\end{array}$

$\mathrm{R}^{2}=0.82, \mathrm{R}^{2}=0.79, \mathrm{~F}=29.4, \mathrm{D} \cdot \mathrm{W} .=1.653$

All the coefficients are significant at 1 per cent level.

On the basis of the above results, the short-run price elasticities of supply are estimated at 0.164 for the period 1963-76 and at 0.17 for the period 1977-85. The absolute magnitudes of price elasticities are not very different from each other. Thus the results indicate that growers' response to price changes has not been significantly higher after -small holdings gained dominance in the coconut production sector.

Finally, another specification of the supply function including the lagged output variable $\left(Y_{t_{1} 1}\right)$. was estimated. Since the time trend variable, $T$, and $Y_{t_{-} 1}$ were highly correlated with each other, the variable $T$ was dropped from this specification. This exclusion is justified as usuafly $Y_{t_{-} 1}$ serves as a proxy for $\mathrm{T}$.

An estimation of this final specification without the intercept dummy (A) lead to a negative coefficient of the price variable. Hence it was decided to include A in this specification. The results of the modified estimation are as foUows:

Supply Function: $\log Y_{t}=f\left(\log P Y_{t_{1}}, \log Y_{t \_}, A\right)(8)$

$$
\text { Coefficient } \quad \text { t statistic }
$$

$\begin{array}{lcr}\text { Constant } & 2.206 & 2.475 \\ \log \mathrm{P}_{\mathrm{t}_{\_} 1} & 0.081 & 1.339 \\ \log \mathrm{Y}_{\mathrm{t}-1} & 0.535 & 3.067 \\ \mathrm{~A} & -0.055 & -2.747 \\ & & \\ \mathrm{R}^{2}=0.71, \mathrm{R}^{2}=0.66, \mathrm{~F}=15.5 . & \end{array}$

Constant term is significant at 2.5 per cent level. The coefficient for $\log \mathrm{P}_{\mathrm{t} \_}$, is significant at 10 per cent level. Coefficients for $\log Y_{t_{-}}$and $A$ are significant at 1 per cent leveL 
As can be seen, the statistical fit of pquation (8) is lower than that of equations (6) and (7). Also, the level of significance of the coefficient for price variable has reduced. However, the coefficient for lagged output variable is significant at 1 per cent level. On the basis of the above resWts, the short-run price elasticity of supply is calculated at 0.081 , the "coefficient of adjustment" at 0.465 (1-0.535), and the long-run price elasticity of supply at 0.17 . The estimates show that current supply of copra depends more significantly on the level of supply in the previous year than on the price in the previous year, that growers are slow in making adjustments to supply in response to changes in prices, and that the level of annual supplies has been shghtly lower before the mid 1970s when large holders dominated the coconut production sector compared to the level of supplies after mid 1970s when small holders gained dominance.

\section{Conclusion}

It is clear from the foregoing discussion that DKL's estimates of price elasticities of copra supply in PNG are unaccepTable mainly because of the inaccuracy of Consumer Price Index data used by them to deflate the producer prices. Also the methodology employed by DKL to estimate long-run price elasticities of supply and to analyse supply response in different situations of large holder and smaH holder dominance in the coconut sector is not appropriate.

The following conclusions emerge from the reestimation of copra supply response functions undertaken in this note: (1) The short-run price responsiveness of PNG coconut growers is much higher than that iznphed in DKL's estimates. For example, the estimates presented in this note (equation 6) show that a 10 per cent increase in price would resalt in 1.6 percent increase in copra production, whereas DKL conclude that a similar change in price would lead to 0.1 percent increase in production. (2) Growers are slow in making adjustments to sapply in response to changes in prices, perhaps caused by the delays in receiving up to, date price infonnation. (3) It is reasonable to beHeve that annual copra suppHes have been slightly higher after mid 1970s with mnaU holdings gaining dominance in the coconut production sector and associated expansion of acreage under coconut cultivation.

\section{ACKNOWLEDGEMENT}

The author w.ishes to thank Paul Barker, Bob Baulch, Hugh Coulter and Euan Fleming for helpful discussions.

\section{REFERENCES}

De Silva, N.T.M.H., Kiele, LJ., and Lagap, A.F. (1987) "Production Response to Prices in the Coconut Industry of Papua New Guinea", CORD, Vol. III No. 2, July 1987, pp. 2-20.

Nerlove, M. (1958). The Dynamics of Supply: Estimation of Farmers'Response to Price. John Hopkins Press, Baltimore.

Tomek. W.G., and Robinson, K-L (1982). Agricultural Product Prices. Cornell University Press, Ithaca. 


\section{APPENDIX 1 : Consumer Price Index Data Used in the Present Estimation}

The Retail Price Index pubhshed in the Statistical Bulletin of 1972 by the Bureau of Statistics of the Territory of Papua and New Guinea, has the base year of 1962, and are given on June-May basis. These, data. were converted to calender year on pro-rata basis. The converted series are as follows

$\begin{array}{cc}\text { Year } & \text { Index } \\ & \\ 1962 & 100 \\ 1963 & 98.15 \\ 1964 & 100.60 \\ 1965 & 105.40 \\ 1966 & 110.15 \\ 1967 & 113.0 \\ 1968 & 114.35 \\ 1969 & 113.85 \\ 1970 & 115.52 \\ 1971 & 123.2\end{array}$

The Abstracts of Statistics pubhshed by the Bureau of Statistics for vahous years during 1972-77 give CPI data taking 1971 as the base year. The CPI figures for 1971-77 are as follows

$\begin{array}{ll}\text { Year } & \text { Index } \\ & \\ 1971 & 100 \\ 1972 & 106.07 \\ 1973 & 114.92 \\ 1974 & 141.55 \\ 1975 & 156.40 \\ 1976 & 168.37 \\ 1977 & 176.00\end{array}$

The above figures are the annual averages of quarterly figures given in the Abstracts of Statistics.

The following CPI figures were extracted from Abstracts of Statistics/Statistical Bulletins published by the National Statistical Office during 1981-85. The data has 1977 as the base year

$\begin{array}{ll}\text { Year } & \text { Index } \\ & \\ 1977 & 100 \\ 1978 & 105.8 \\ 1979 & 111.9 \\ 1980 & 125.4 \\ 1981 & 135.5 \\ 1982 & 143.0 \\ 1983 & 154.3 \\ 1984 & 165.8 \\ 1985 & 171.9\end{array}$

The different series were converted to a common base year $(1985=100)$, applying the simple straight line convertion method. The convertion was in several steps. First, figures from 1962 to 1970 were converted for 1971=100. Second, figures from 1962 to 1976 were converted setting 1977=100. 
FinaUy, the figures fiom 1962 to 1984 were converted for the base where 1985=100. The converted CPI figures, which were used in deflating producer price are as follows

$\begin{array}{ll}\text { Year } & \text { Index } \\ & \\ 1962 & 26.30 \\ 1963 & 25.82 \\ 1964 & 26.45 \\ 1965 & 27.72 \\ 1966 & 28.97 \\ 1967 & 29.72 \\ 1968 & 30.07 \\ 1969 & 29.94 \\ 1970 & 30.38 \\ 1971 & 32.48 \\ 1972 & 34.44 \\ 1973 & 37.32 \\ 1974 & 45.97 \\ 1975 & 50.79 \\ 1976 & 54.68 \\ 1977 & 58.00 \\ 1978 & 61.36 \\ 1979 & 64.90 \\ 1980 & 72.73 \\ 1981 & 78.59 \\ 1982 & 82.94 \\ 1983 & 89.49 \\ 1984 & 96.16 \\ 1985 & 100\end{array}$


APPENDIX 2 : Copra Production and Price Data Used in the Estimation.

$\begin{array}{cc}\text { Year } & \begin{array}{c}\text { Production } \\ \text { (Tonnes) }\end{array} \\ \text { Nominal Producer Price } \\ \text { (Kina/Tonne) }\end{array}$

$\begin{array}{lll}1962 & 110,639 & 118 \\ 1963 & 106,696 & 134 \\ 1964 & 114,339 & 144 \\ 1965 & 122,340 & 171 \\ 1966 & 114,209 & 137 \\ 1967 & 115,211 & 148 \\ 1968 & 136,556 & 171 \\ 1969 & 128,444 & 146 \\ 1970 & 128,947 & 163 \\ 1971 & 137,827 & 142 \\ 1972 & 131,736 & 113 \\ 1973 & 125,438 & 197 \\ 1974 & 137,236 & 368 \\ 1975 & 139,369 & 165 \\ 1976 & 123,252 & 174 \\ 1977 & 134,004 & 237 \\ 1978 & 145,927 & 252 \\ 1979 & 160,136 & 344 \\ 1980 & 148,373 & 249 \\ 1981 & 146,867 & 223 \\ 1982 & 138,128 & 172 \\ 1983 & 137,527 & 240 \\ 1984 & 158,224 & 387 \\ 1985 & 175,833 & 310\end{array}$

Source: De Silva, Kiele and Lagap (1987), P. 10. 